\title{
Investigations of phytochemical and antifungal activity of Carica papaya $\mathrm{L}$. leaves
}

Qumqum Noshad, Musfirah Anjum*, Nafeesa Zahid Malik, Muhammad Ajaib, Sadia Jehangir and Muhammad Riaz

Department of Botany (Bhimber Campus), Mirpur University of Science\&Technology (MUST), Mirpur-10250

(AJK)-Pakistan

*Corresponding author's email:Musfirah.anjum@yahoo.com

Citation

Qumqum Noshad, Musfirah Anjum*, Nafeesa Zahid Malik, Muhammad Ajaib, Sadia Jehangir and Muhammad Riaz. Investigations of phytochemical and antifungal activity of Carica papaya L. leaves. Pure and Applied Biology. Vol. 7, Issue 1, pp309-314. http://dx.doi.org/10.19045/bspab.2018.70037

\begin{tabular}{llll}
\hline \hline Received: 09/01/2018 & Revised: 23/02/2018 & Accepted: 26/02/2018 & Online First: 27/02/2018
\end{tabular}

\section{Abstract}

The present work was performed to investigate the phytochemical and antifungal action of Carica papaya L. of family Caricaceae. C. papaya is an important tropical fruit also cultivated in Pakistan and Azad Jammu \& Kashmir. The leaves of the respective plant contain a number of important secondary metabolites. In the present investigation, we studied the phytochemical analysis of carbohydrate, protein, phenolic compounds and many other secondary metabolites. Antifungal effectiveness was determined by using different leaf extracts of $C$. papaya against Aspergillus flavus, Aspergillus niger, Fusarium sp. and Cladosporium sp. The plants methanolic leaf extracts showed better activity against Aspergillus niger, Cladosporium sp. and Fusarium sp., ethanolic leaf extracts showed pronounced inhibition against Aspergillus niger, Aspergillus flavus and Cladosporium sp. While aqueous leaf extracts did not show inhibitory action against these fungi. Keywords: Antifungal activity; Phytochemical constituents; Secondary metabolites

\section{Introduction}

Carica papaya also famous as pawpaw is commonly grown in tropical Africa, it is a berry type fruit with parietal placentation [1]. Even though beliefs are different on the origin of C. papaya in tropical America but it is expected that $C$. papaya originates from the lowlands of ECA (Eastern Central America), from Panama to Mexico [2].

Mallikharjuna et al. [3] stated that phytochemicals are active secondary metabolites that have potential to protect plant from external stimuli and cure diseases. These secondary metabolites act as a natural defense system against environmental stimuli and give odor, flavor and pigmentation to the plant. The antimicrobial ability of extracts of plants are due to these secondary metabolites, included, i.e., flavonoids, alkaloids, glycosides, saponins, tannins, terpenoids, sterols and carbohydrates. Qualitative phytochemical screening of $C$. papaya reveals that it contains bioactive chemical substances i.e., flavonoids, alkaloids, glycosides, saponins, tannins and anthraquinones [4].

Plants plays a significant role as compare to animals in our lives, due to the presences of 
different types of biochemical and biological compounds [5]. For many years in pharmaceutical industry plants are used as a source of medicines especially due to the presence of phytochemicals [6]. Many people recommended to cultivate wild plants as a source of medicines due to increase their popularity the demand of such plant has also been increased [7]. On the basis of natural products almost $61 \%$ of the drug development occurred between 1981 and 2002 and these drugs have great success against certain diseases, infectious diseases and cancer are on the top of the list. In recent eras the decline in the discovery rates of active chemicals and entities is seen. Some of these secondary metabolites singly or in combination can inhibit microbes, especially that cause diseases [8].

\section{Statement of the problem}

This study aimed to evaluate the phytochemical and antifungal activity of Carica papaya against selected species of fungus.

\section{Material and methods \\ Plant material}

The fresh leaves of Papaya were collected from different sites of Bhimber District, AJK. The plant specimen was identified from herbarium MUST, Bhimber Campus and voucher no. MUST. BOT. 5360 was obtained for further reference.

\section{Phytochemical investigation}

Phytochemical investigation carried out by using the method given by Sofowara, (1993) [9] and Harborne, (1973) [10].

\section{Drying of leaves}

Leaves plant was separated and washed with water, then dried at room temperature. By using pestle and mortar the dried plant material was finely grounded.

\section{Extract preparation}

For extract preparation $20 \mathrm{~g}$ of leaves powder was soaked in $100 \mathrm{ml}$ water for a week. Then extract was filtered by using filter paper
Whattman No.1 and by using a rotary evaporator made extract more concentrated.

The same procedure was used to make the ethanolic extract. Then for overnight, this extract was placed in aqueous, ethanol and methanol extracts. The extracts that obtained after evaporation, these extracts were used for phytochemical investigation for the presence of alkaloids, flavonoids, saponins, terpenoids, carbohydrates, glycosides, protein, sugars, phenols and tannins etc.

\section{Qualitative analysis}

Test for alkaloids

By adding $1 \mathrm{ml}$ of plant extract and adding with a few drops of Mayer's reagent. Appearance of cream or pale yellow precipitates indicated the presence of alkaloids. Another method was by adding $1 \mathrm{ml}$ of plant extract and few drops of Dragendroff's reagent. Orange ppt. indicated the presence of alkaloids [11].

\section{Test for tannins}

Few drops of $0.1 \%$ Ferric chloride was added in $1 \mathrm{ml}$ sample plant extract. Appearance of brownish green or blue black colour indicated the presence of tannins.

\section{Test for saponins}

$2 \mathrm{ml}$ of plant extracts and $2 \mathrm{ml}$ of distilled water shaken continuously. If stable, persistent froth for $5 \mathrm{mint}$, indicated the presence of saponins.

\section{Test for flavonoid}

$3 \mathrm{ml}$ of ammonia solution and few drops of $\mathrm{H}_{2} \mathrm{SO}_{4}$ was added in $2 \mathrm{ml}$ of plant sample extract, Yellow colour formation indicated the presence of flavonoids.

\section{Test for steroids}

$0.5 \mathrm{~g}$ of ethanolic plant extract was dissolved in $2 \mathrm{ml}$ of $\mathrm{H}_{2} \mathrm{SO}_{4}$. Colour changed from violet to blue or green, confirmed the presence of steroids.

\section{Test for glycosides}

$1 \mathrm{ml}$ of plant extract was added with $2 \mathrm{ml}$ of acetic acid and a drop of $\mathrm{FeCl}_{3}$ then $1 \mathrm{ml}$ of Conc. $\mathrm{H}_{2} \mathrm{SO}_{4}$. Appearance of violet colour 
ring below the brown layered ring indicated the presence of glycosides..

Test for phenols

Few drops of $\mathrm{FeCl}_{3}$ solution was added in $1 \mathrm{ml}$ of plant extract. Appearance of intense colouration, suggested the indication of phenol.

\section{Test for carbohydrates}

Few drops of alcoholic alpha-naphthol was added in $2 \mathrm{ml}$ of plant extract sample, then Conc. $\mathrm{H}_{2} \mathrm{SO}_{4}$ was added along the wall of test tube. Formation of purple to violet colour ring at the junction, confirmed the indication of carbohydrates.

\section{Test for protein}

Test sample of $2 \mathrm{ml}$ was heated in the water bath till boiling. Coagulation of proteins indicated the presence of proteins.

\section{Antifungal evaluation}

By using agar well diffusion method, the antifungal activity of $C$. papaya leaves was investigated that was used followed by Mazher et al. [12]. The antifungal activity was investigated against Aspergillus flavus, Aspergillus niger, Fusarium sp. and Cladosporium sp.

Investigation of minimum inhibition concentration (MIC)

MIC of plant extracts of $C$. papaya was assessed by the method adopted by Adebayo et al. [13].

\section{Results and discussion}

Phytochemical analysis showed the presence and absence of phytochemical constituents in methanolic, ethanolic and aqueous leaf extracts of Carica papaya L. In methanolic extract the phytochemicals present was alkaloids, saponins, flavonoids, steroids, tannins, glycosides and proteins while phenolic compounds and carbohydrates were absent. In extract of ethanol saponins, alkaloids, flavonoids, glycosides, steroids and carbohydrates were indicated,while phenolic compounds and tannins were absent. Aqueous extract only showed the presence of alkaloids as shown in (Table 1).

Methanolic, ethanolic and aqueous extracts were used to check the antifungal activity of Carica papaya leaves against selected fungal strains A. flavus, Cladosporium sp. A. niger, and Fusarium sp. Methanolic extract showed the better activity against $A$. flavus, Fusarium sp. and Cladosporium sp. as shown in (Table 2, Figure 1). While the ethanolic extract was more effective against $A$. niger and Aspergillus flavus as shown in (Table 2, Figure 2). Aqueous extract did not show antifungal activity.

Phytochemical analysis revealed that the methanolic extract of selected plant contained saponins, glycosides, steroids, tannins, flavonoids, proteins and alkaloids. Carbohydrates and phenolic compounds were absent in methanolic macerate of the leaves. While the ethanolic leaves macerates contained carbohydrates, proteins,steroids, glycosides, alkaloids, flavonoid and saponins.

Table 1. Phytochemical analysis of Carica papaya leaves

\begin{tabular}{|c|c|c|c|}
\hline Phytochemicals & \multicolumn{3}{|c|}{ Extracts of Plant } \\
\hline & Methanol & Ethanol & Aqueous \\
\hline Flavonoids & + & + & -- \\
\hline Alkaloids & + & + & + \\
\hline Saponins & + & + & -- \\
\hline Sterols & + & + & -- \\
\hline Phenolic compounds & -- & -- & -- \\
\hline Tannins & + & -- & -- \\
\hline Glycosides & + & + & -- \\
\hline Proteins & + & + & -- \\
\hline Carbohydrates & -- & + & -- \\
\hline
\end{tabular}


Table 2. Antifungal activity of Methanolic and Ethanolic extracts of Carica papaya leaves

\begin{tabular}{|c|c|c|c|c|c|}
\hline \multirow{2}{*}{ Conc. } & & \multicolumn{3}{|c|}{ Zone of Inhibition (mm) } & \\
\cline { 3 - 6 } & $\begin{array}{c}\text { Aspergillus } \\
\text { niger }\end{array}$ & $\begin{array}{c}\text { Aspergillus } \\
\text { flavus }\end{array}$ & $\begin{array}{c}\text { Cladosporium } \\
\text { sp. }\end{array}$ & $\begin{array}{c}\text { Fusarium } \\
\text { sp. }\end{array}$ \\
\hline \multirow{2}{*}{$\mathbf{1 ~} \mathbf{~ m g / m l}$} & Methanol & $0.00 \pm 0.00$ & $5.0 \pm 0.00$ & $0.00 \pm 0.00$ & $0.00 \pm 0.00$ \\
\cline { 2 - 6 } & Ethanol & $0.134 \pm 0.27$ & $3.10 \pm 0.01$ & $1.00 \pm 0.37$ & $0.00 \pm 0.00$ \\
\hline \multirow{2}{*}{$\mathbf{5} \mathbf{~ m g / m l}$} & Methanol & $5.06 \pm 0.11$ & $7.00 \pm 0.57$ & $8.0 \pm 0.20$ & $8.23 \pm 0.25$ \\
\cline { 2 - 6 } & Ethanol & $7.03 \pm 0.1$ & $9.22 \pm 0.02$ & $5.10 \pm 0.22$ & $0.00 \pm 0.00$ \\
\hline \multirow{2}{*}{$\mathbf{2 0} \mathbf{~ m g / m l}$} & Methanol & $19.68 \pm 0.70$ & $17.55 \pm 0.89$ & $9.30 \pm 0.26$ & $8.0 \pm 0.00$ \\
\cline { 2 - 6 } & Ethanol & $20.00 \pm 0.45$ & $18.45 \pm 0.5$ & $11.51 \pm 0.02$ & $0.56 \pm 0.1$ \\
\hline
\end{tabular}

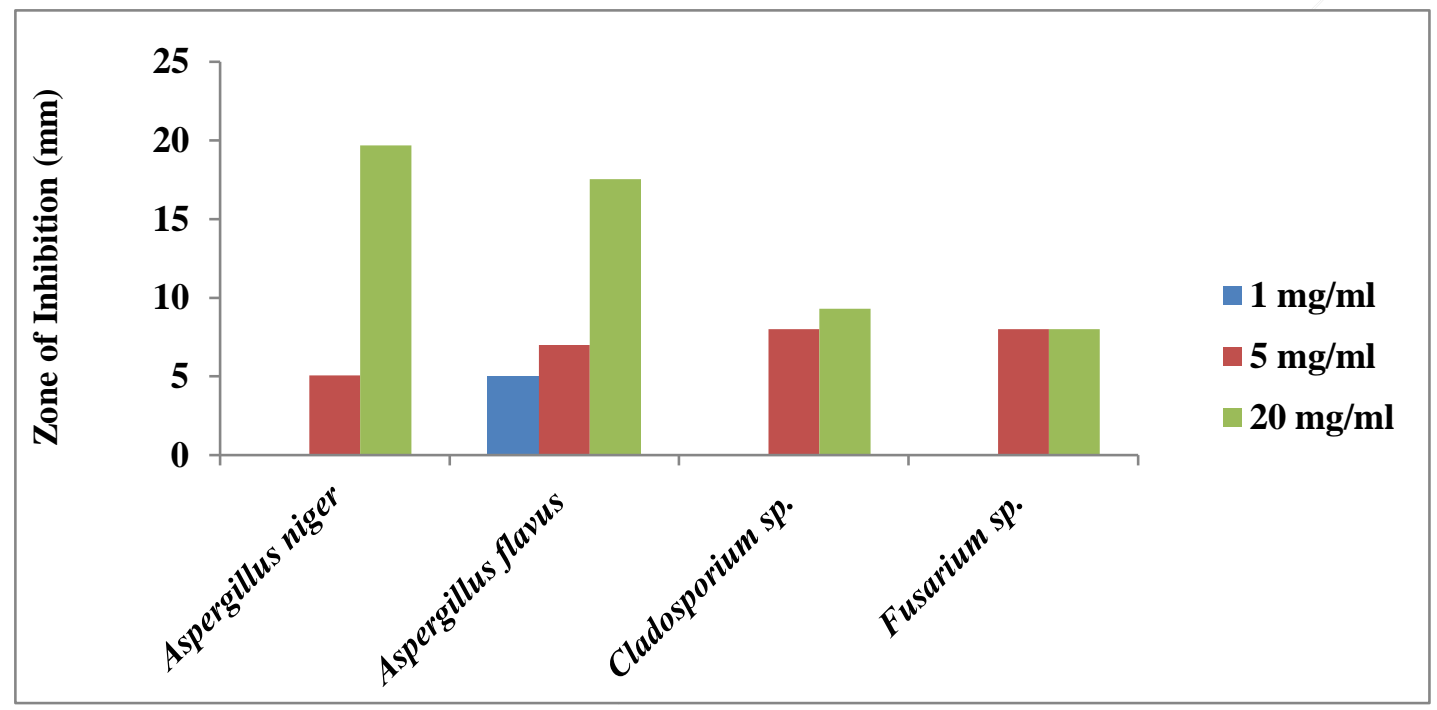

Figure 1. Graphical representation of Antifungal activity of Methanolic extract of Carica papaya leaves

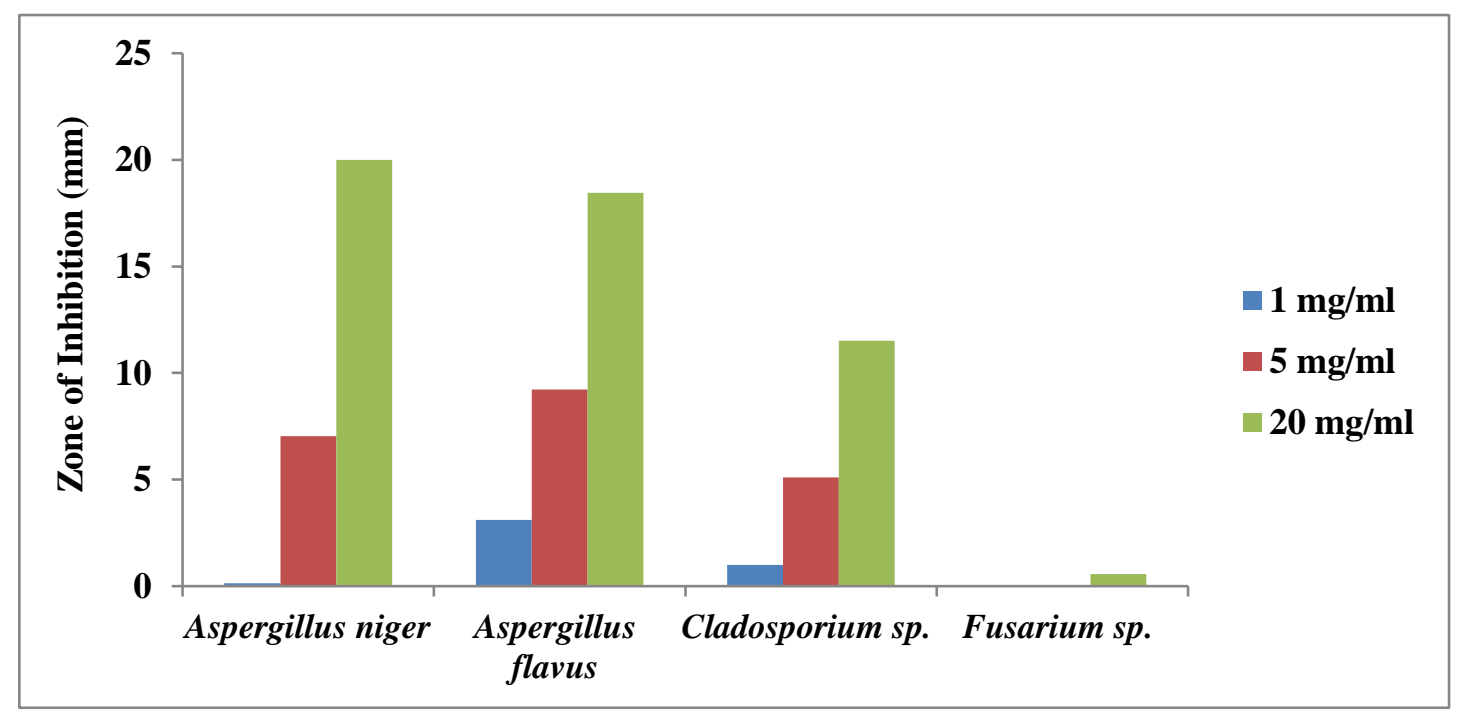

Figure 2. Graphical representation of Antifungal activity of Ethanolic extract of Carica papaya leaves 
Phenolic compounds and Tannins were absent in the ethanolic extract of leaves. The The leaves of $C$. papaya has cytotoxic effect, i.e., permeabilization of the intestine because saponins are present in the leaves and as cytotoxic property. The bitter taste of leaves are also due to saponins. Saponins are also associated with sex hormones i.e., oxytoxin that involved in labor pain in women [14]. Alkaloids are the most important secondary metabolites and have a therapeutic action to cure diseases. The pure alkaloids and synthetic derivatives used as medicinal agents because of its antimicrobial, antimalarial, analgesic etc activities [15]. The alkaloids are present in the leaves of selected plant so, this plant can be used. They show marked physiological effects when administered to animals. The presence of alkaloids in the leaves shows that these plants can be used in effective anti-malarial drug. Glycosides that present in the leaves of plant have ability to increase the power of heartbeat without increasing the amount of oxygen that needed by heart. They can thus increase the efficiency [16].

Papaya (Carica papaya L.) is an important fruit in the tropics including Pakistan. In the following study survey was carried in a few regions of District Bhimber C. papaya Linn was evaluated for phytochemical analysis by using different organic solvents to determine the type of constituents present in medicinal plant material. Phytochemical analysis was performed on different leaf extracts confirmed the presence of alkaloids, glycosides, saponins, tannins, flavonoids, proteins, etc. after that extracts with different concentrations was used to check the antifungal activity of $C$. papaya $\mathrm{L}$. leaves. The present results clearly showed that the methanolic and ethanolic extracts have shown better antifungal activity against the entire tested organisms while aqueous extract was not effective against tested organisms. At the concentration of $1 \mathrm{mg} / \mathrm{ml}$ no inhibition aqueous extract of leaves has shown only the presence of alkaloids.

zones were observed, methanolic extract showed little inhibition against Aspergillus flavus. While at the concentration of 20 $\mathrm{mg} / \mathrm{ml}$ both extracts showed the better inhibition. Ethanol extracts were more effective against Aspergillus niger, Aspergillus flavus and Cladosporiumsp. Methanol extract was more effective against and A. flavus, Cladosporium sp. and Fusarium sp. These results have shown that C. papaya leaves are effective against various fungi. Baskaran et al., (2012) has same worked on phytochemical and antifungal activity of $C$. papaya, acetone extract in fungus showed a varying degree of inhibition to the growth of tested organism [17].

\section{Conclusion}

The present study revealed that extracts of leaves of Carica papaya L. showed significant antimicrobial activity and have secondary metabolites. Thus, this investigation gives a strong impact for increasing the search of natural antimicrobials for use in health cares systems and food industry. The antimicrobial activity of the compounds present in different extracts was strong, but it is strongly recommended for further investigation on purified/isolated individual compounds.

\section{Authors' contributions}

Conceived and designed the experiments: Q Noshad, Performed the experiments: M Anjum \& S Jehangir, Analyzed the data: M Ajaib, Contributed materials/ analysis/ tools: N Z Malik \& M Riaz, Wrote the paper: M Anjum.

\section{References}

1. Kochhar SL (1986). Tropical crops, a textbook of economic Botany. 263-264: 323-326.

2. Nakasone HY \& Paull RE (1998). Tropical fruits, CAB International, Wallingford. A trees from a tropical rain 
forest region in Mexico. Tree Physiology 18(4): 277-280.

3. Mallikharjuna PB, Rajanna SN, Seetharam YN \&Sharanabasappa GK (2007). Phytochemical studies of Strychnospotatorum L. f. A medicinal plant. Ethnobot J Chem 4(4): 510-5.

4. Edeoga HO, Okwu DE \& Mbaebie BO (2005). Phytochemical constituents of some Nigerian medicinal plants. Afri $J$ Biotech 4(7): 685-688.

5. Buckingham J. Dictionary of Natural Compounds. Hapman and Hall, U.K: 1420 (1999).

6. Agarwal SG \& Goyal S (2013). Nycanthes arbor-tristis Against Pathogenic Bacteria. $J$ Pharmaco Phytochem 2(3): 124-127.

7. Ajaib M, Khan A, Abbasi MA \& Riaz T (2013). Antimicrobial screening of Iris aitchisonii (Bakar) Boiss. Biologia (Pak) 59(1): 51-55.

8. Cragg GM \& Newman DJ (2005). Biodiversity: A continuing source of novel drug leades. Pure Appl Chem 77: 7-24.

9. Sofowara AE (1993). Medicinal plants and traditional medicine in Africa. Spectrum Books Ltd., Ibadan. 2:288.

10. Harborne JB (1973). Phytochemical methods, a guide to modern techniques of plant analysis. Chapman and Hall, London. 49-279.
11. Qadeer M, Mushtaq W, Ishtiaq M, Anjum M, Faisal M \& Mazhar M (2017) Comparative in vivo antidiabetic evaluation of leaves and bark of Berberis lycium Royle in alloxan induced diabetic rabbits. Int J Biosci 11(1): 449-456.

12. Mazher M, Anjum M, Mushtaq W, Noshad Q \& Malik NZ (2017). Antifungal assay of Solanum nigrum Linn. fruit, leaves and stem extracts in different solvents. Int J Biosci 10(4): 380-385.

13. Adebayo AC, Oloke JK \&Aladesanmi AJ (1989). Antimicrobial activities of the leaf of Eugenia uniflora. Phytotherapy 3(6): 258-259.

14. Okwu DE \&Okwu ME (2004). Chemical composition of Spondiamombin plants. $J$ Sustain Agri Environ 6: 140-147.

15. Stray F (1998). The natural guide to medicinal herbs and plants. Tiger Books International, London. 12-16.

16. Robinson $\mathrm{T}$ (1985). The organic constituents of higher plants. Their Chemistry and Interrelationships. Corcleus Press. North Amherst mass 6 (3): 430-435.

17. Baskaran C, Ratha BV, Velu S\& Kumaran K (2012). The Efficacy of Carica papaya Leaf Extract on some Bacterial and Fungal Strain by Well Diffusion Method.Asian Pacific J Tropi Disea 2: 658-662. 